\title{
Gene Expression Profile of Bioreactor-Cultured Cardiac Cells: Activation of Morphogenetic Pathways for Tissue Engineering
}

\author{
ROBERT E. AKINS, ${ }^{1}$ KARA GRATTON,${ }^{1}$ EMILIO QUEZADA, ${ }^{1}$ HEATHER RUTTER, ${ }^{1}$ \\ TAKESHI TSUDA, ${ }^{1}$ and PATRICIA SOTEROPOULOS ${ }^{2}$
}

\begin{abstract}
Cells grown in three-dimensional (3D) culture take on in vivo phenotypes and organize into tissue-like structures. Understanding the pathways and mechanisms contributing to this in vitro tissuegenesis is a critical goal of tissue engineering. To identify pathways relevant to cardiac tissue engineering, we compared mRNA expression profiles from bioreactor-cultured 3D aggregates of primary neonatal rat heart cells (NRHCs), which form layered structures similar to cardiac tissue, and standard plate-cultured NRHCs, which do not. In a series of two experiments, NRHCs were grown on solid microcarrier surfaces within clinostatically rotated polytetrafluoroethylene (PTFE) vessels and compared to parallel cultures grown on standard tissue culture plates without rotation. After 1, 4, and 6 days, gene expression profiles were analyzed using Affymetrix Rat Genome U34A (RG-U34A) arrays. The results were validated using real-time PCR, and the data set was filtered to generate a list of 93 probe sets that were substantially the same in replicate samples but substantially different between the bioreactor and plate groups. Cluster analysis indicated that the bioreactor and plate samples had similar expression patterns on day 1 but that these patterns diverged thereafter. Database for Annotation, Visualization, and Integrated Discovery (DAVID) analysis revealed a number of statistically significant gene groupings, including groups associated with muscle development and morphogenesis. Further analysis of the annotated gene list indicated that 13 of the 93 filtered genes were associated with endothelial cells, blood vessels, or angiogenesis. These results suggest that 3D aggregate culture of NRHCs in bioreactors is associated with the differential expression of morphogenic and angiogenic pathways similar to those seen during cardiac development.
\end{abstract}

\section{INTRODUCTION}

$\mathbf{T}$ HE CULTURE OF CELLS in three-dimensional (3D) aggregates results in cellular phenotypes and multicellular organizations similar to those seen in vivo (Bissell et al., 2003). Understanding this process, termed in vitro tissuegenesis (National Institutes of Health, 1999), and identifying the pathways contributing to the formation of tissue architecture in vitro are central goals in tissue engineering and regenerative medicine research. Cardiac tissuegenesis is of particular concern due to the high morbidity and mortality associated with congenital and acquired heart disease (Thom et al., 2006) and the clinical need for new approaches to battle cardiovascular disease (Eschenhagen and Zimmermann, 2005).
Primary cardiac cells are a useful model for in vitro studies of cardiac tissuegenesis. Primary cardiac cells grown on tissue culture plates form two-dimensional (2D) mosaic patterns in which patches of cardiomyocytes associate laterally with neighboring cells (McCarl et al., 1980). Studies utilizing 3D aggregate culture systems, on the other hand, demonstrate that heart cells are capable of assembling multicellular structures similar to those seen in vivo (Sperelakis, 1978; Akins et al., 1997, 1999; Akins and Sefton, 2001; Zimmermann et al., 2002; Kelm et al., 2004; Watzka et al., 2004; Baar et al., 2005; Birla et al., 2005b). In particular, neonatal rat heart cells (NRHCs) grown in clinostatically rotated bioreactors have been shown to form tissue-like structures even in the absence of 3D scaffolds or other organizational cues (Akins et al., 1999). Direct comparisons between 2D plate and

\footnotetext{
${ }^{1}$ Nemours Biomedical Research, A.I. duPont Hospital for Children, Wilmington, Delaware.

${ }^{2}$ Center for Applied Genomics, Public Health Research Institute, Newark, New Jersey.
} 
3D bioreactor cultures indicate that differences in multicellular organization arise even when the overall cellular composition, metabolic activities, and sarcomeric protein expression levels in the two systems are nearly identical (Akins et al., 1999; Akins and Sefton, 2001). These observations suggest that the differential patterning of cardiac cells in 3D aggregate culture may result from alterations in cell-cell interactions and cell migration rather than from differences in the cellular composition relative to $2 \mathrm{D}$ cultures. To investigate this possibility and to begin elucidating the pathways associated with in vitro cardiac tissuegenesis, we compared gene expression profiles over time between NRHCs grown in bioreactor and plate cultures.

\section{MATERIALS AND METHODS}

\section{Cell isolation and culture}

Cultures of NRHCs were prepared on two separate occasions using the procedures approved by Institutional Animal Care and Use Committee. Each time, newborn Sprague-Dawley rats (Charles River, MA) were humanely euthanized 2 days after birth, and cardiac ventricular cells were collected using Neonatal Cardiomyocyte Isolation Kits (Worthington, Lakewood, NJ). To limit cell proliferation and encourage interactions, cultures were inoculated at high density in a serum-free medium as described previously (Akins, 2002). Briefly, cultures were initiated at a density of $1 \times 10^{6}$ viable cells per mL of medium per $4.8 \mathrm{~cm}^{2}$ of Nunclon $^{\mathrm{TM}} \Delta$ polystyrene surface (Nalge-Nunc International, Rochester, NY) using standard six-well plates for controls and microcarriers for bioreactor cultures. Cells were grown in a custom, serum-free medium (AI-1 medium) comprising a 1:1 mixture of Dulbecco's modified Eagle's and Ham's F-12 media, with $1 \times$ minimum essential medium (MEM) nonessential amino acids, $1 \times$ MEM vitamin solution, $2.45 \mathrm{mg} / \mathrm{mL}$ sodium bicarbonate, $100 \mathrm{U} / \mathrm{mL}$ penicillin, $100 \mathrm{U} / \mathrm{mL}$ streptomycin (all from Invitrogen, Carlsbad, CA), $20 \mu \mathrm{g} / \mathrm{mL}$ sodium ascorbate, $0.25 \mathrm{mg} / \mathrm{mL}$ fetuin, $0.0835 \mathrm{mg} / \mathrm{mL}$ calcium chloride, $0.001 \mu \mathrm{g} / \mathrm{mL}$ sodium selenate, $1.35 \mathrm{mg} / \mathrm{mL}$ additional dextrose, $0.01 \mu \mathrm{g} / \mathrm{mL}$ epidermal growth factor, $75 \mathrm{pg} / \mathrm{mL}$ tri-iodothyronine, $0.05 \mu \mathrm{g} / \mathrm{mL}$ hydrocortisone, $0.05 \mathrm{mU} / \mathrm{mL}$ insulin (all from Sigma-Aldrich, St. Louis, MO), $5 \mu \mathrm{g} / \mathrm{mL}$ holo-transferrin (BD Biosciences, Bedford, MA), $1 \mathrm{mg} /$ $\mathrm{mL}$ bovine serum albumin (BSA) (Mediatech, Herndon, VA), and $1 \mu \mathrm{M}$ palmitate (Sigma) preconjugated with $0.12 \mathrm{mg} / \mathrm{mL}$ fatty-acid-free BSA (Roche Diagnostics, Indianapolis, IN) as carrier. Microcarrier-based cultures were grown in closed, nonperfused VueLife ${ }^{\mathrm{TM}}$ containers (American Fluoroseal, Gaithersburg, MD) that were rotated around a horizontal axis at $37.5 \mathrm{rpm}$ to suspend the contents. Rotation was interrupted and cultures fed $24 \mathrm{~h}$ after initiation and at 48-h intervals thereafter. Cellular protein and DNA content were determined as described previously (Akins et al., 2004).

\section{Affymetrix GeneChip analysis}

Total RNA was isolated from culture samples using TriReagent (Molecular Research Center, Cincinnati, OH) with bromochloropropane. For plate cultures, medium was aspirated, and $1.0 \mathrm{~mL}$ Tri-Reagent was added to each well. Cells were scraped and collected in sterile Eppendorf tubes. VueLife bags were emptied into $15-\mathrm{mL}$ conical tubes, the microcarriers were permitted to settle, and the medium was aspirated. One milliliter of Tri-Reagent was added to the microcarriers. Each sample was vortexed, and the microcarriers were allowed to float to the surface. The Tri-Reagent beneath was collected into sterile Eppendorf tubes, and the RNA fraction collected. RNA was further purified using RNEasy kits (Qiagen, Valencia, CA) following the manufacturer's protocol. Double-stranded cDNA was prepared using a $\mathrm{T}_{7}$-oligo-dT primer $\left(\mathrm{T}_{7}-\mathrm{dT}_{24}\right.$; Integrated DNA Technologies, Coralville, IA) and SuperScript Double Stranded cDNA Synthesis Kits (Invitrogen). $\mathrm{T}_{7}$-polymerase-based in vitro transcription and biotin labeling were performed using the BioArray HighYield RNA Transcription Kit (Enzo Life Sciences, Farmingdale, NY). The labeled cRNA was hybridized to the GeneChip Rat Genome U34A (RG-U34A) array (Affymetrix, Santa Clara, CA). Following hybridization, the hybridization mixture was removed and the arrays were washed and stained with Rphycoerythrin streptavidin (Molecular Probes, Eugene, OR) using the GeneChip Fluidics Station 400 and the EukGE-WS2 fluidics protocol. The chips were scanned using an Affymetrix GeneArray Scanner. Numeric data were extracted from images and normalized using the Microarray Suite 5 (MAS5) software (Affymetrix). Signals on each chip were mean centered to a value of 500 based on a scaling factor calculated from the middle $96 \%$ of signal values.

Probe sets were included in the data set if the absolute value of the $\log _{2}$ signal ratio was $<1.00$ (i.e., less than twofold difference) or if the signal was called absent in both partners in all of the six following comparisons: (i) bioreactor day 1/Culture-A (Bio-1A) versus bioreactor day $1 /$ Culture $\mathrm{B}$ (Bio-1B), (ii) Bio-4A versus Bio-4B, (iii) Bio-6A versus Bio-6B, (iv) Plate-1A versus Plate$1 B$, (v) Plate-4A versus Plate-4B, and (vi) Plate-6A versus Plate$6 \mathrm{~B}$. The data set was further filtered such that probe sets were only included in the subsequent analyses if the signal was absent in one but present in the other, or if signal was present in both with the absolute value of the $\log _{2}$ signal ratio $>1.00$ (i.e., greater than twofold difference) for any of the six following comparisons: (i) Bio-1A versus Plate-1A, (ii) Bio-1B versus Plate-1B, (iii) $\mathrm{Bio}-4 \mathrm{~A}$ versus Plate- $4 \mathrm{~A}$, (iv) Bio- $4 \mathrm{~B}$ versus Plate-4B, (v) Bio-6A versus Plate-6A, and (vi) Bio-6B versus Plate-6B.

\section{Real-time PCR}

Real-time quantitative PCR (qPCR) was carried out using a single-color BioRad My-iQ detection system and iScript OneStep RT-PCR Kits with SYBR Green (BioRad, Hercules, CA). The primer pairs used for PCR are listed in Table 1.

\section{Data analysis}

Hierarchical clustering (Eisen et al., 1998), statistical analyses, and data visualization were performed using The Institute for Genome Research (TIGR) Multiple Experiment Viewer (TMEV, version 4.0) from the TM4 Microarray Software Suite (Saeed et al., 2003). For hierarchical clustering, values were normalized by taking the absolute difference between a given probe set value and the probe set mean across all 12 samples and dividing it by the standard deviation for those values. Gene-list annotations and Expression Analysis Systematic Explorer (EASE) analysis (Hosack et al., 2003) were carried out using the Database for Annotation, Visualization, and Integrated Discovery (DAVID) (Dennis et al., 2003). 
Table 1. Real-Time Quantitative PCR Primer Pairs ${ }^{\mathrm{a}}$

\begin{tabular}{lll}
\hline Gene & \multicolumn{1}{c}{ Forward primer } & \multicolumn{1}{c}{ Reverse primer } \\
\hline ADAM-17 & TACCCACACGGTGGCTCTTAA & GCATGTTTGACTGCACCAATG \\
Collagen III & AGCTGGACCAAAAGGTGATG & GACCTCGTGCTCCAGTTAGC \\
NppA & ATCACCAAGGGCTTCTTCCT & TGTTGGACACCGCACTGTAT \\
Myh6 & GAGAAGGAAAAGCACGCAAC & CTTCTCCTTGGTCAGCTTGG \\
Troponin I & GCTCGTGTGGACAAAGTGGATG & TTATTCCTCAGAGATGCCCTTCAG
\end{tabular}

${ }^{\mathrm{a}}$ All sequences are listed $5^{\prime}$ to $3^{\prime}$.

\section{RESULTS}

\section{Validation of array expression patterns}

Bioreactor and plate cultures prepared under the conditions applied in this study have been found to be remarkably similar in cellular content and metabolic activities, but dramatically different in multicellular organization (Akins et al., 1997, 1999; Akins and Sefton, 2001). Consistent with this observation, the ratio of protein to DNA and the level of cardiac-specific troponin I (TnI) expression were virtually identical in plate and bioreactor samples from the present set of experiments (Fig. 1). Thus, the comparison of expression patterns between the two culture systems was expected to identify differences associated with previously described cell patterning rather than differences in cell content.

To determine whether the expression profiles obtained from the microarrays were consistent with the relative amounts of mRNA present in the samples, $\mathrm{qPCR}$ validation was carried out on the RNA samples used for GeneChip analysis. As shown in Figure 2, the normalized expression patterns determined from Affymetrix chip signals for select genes (ADAM-17, Col3A, $\mathrm{NppA}$, and Myh6) were similar to those determined by realtime PCR, and although differences in magnitude were apparent for Col3A, overall the results indicated that the pattern of expression seen in the chip analysis reflected the pattern of mRNA expression in the samples. The expression patterns for these clusters are shown graphically in Figure 4.

\section{Association among samples and probe sets}

Data from 12 arrays were collected in this experiment. These represented day 1 , day 4 , and day 6 time points collected from bioreactor and plate cultures performed in two separate experiments. Analysis yielded 4,650 probe sets that were present at least once on the 12 chips. Systematic reduction of this data set was carried out to identify genes and pathways of particular interest, and a set of genes with expression levels that were substantially the same within replicate samples but substantially different between bioreactor and plate groups was generated. Filtering in this way yielded 93 probe sets. To analyze associations among the 93 probe sets, the average ratio of bioreactor to plate signal was calculated for each day. The $\log _{2}$ values were used in a hierarchical clustering analysis based on Pearson's correlation and average linkage. Probe sets that exhibited similar changes over time in culture were identified. As seen in Figure $3 \mathrm{~A}$, nine distinct clusters were found.

To further analyze associations among samples, hierarchical clustering was also applied to the normalized values of all 12 samples, and, as shown in Figure 3B, interesting groupings were found. All four samples from day 1 (Bio-1A, Bio-1B, Plate-1A, and Plate-1B) clustered together, whereas the remaining bioreactor (Bio-4A, Bio-4B, Bio-6A, and Bio-6B) and plate (Plate-4A, Plate-4B, Plate-6A, and Plate-6B) samples formed two additional clusters. Thus, bioreactor and plate expression patterns appeared similar on day 1 but diverged thereafter.

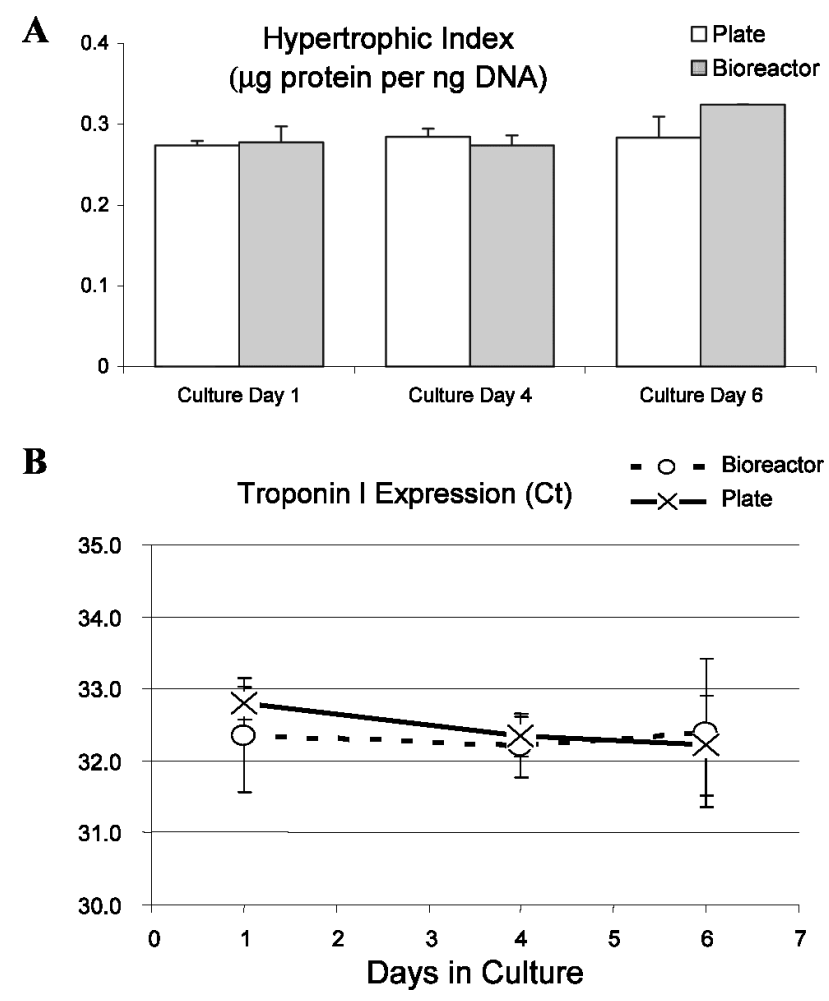

FIG. 1. Similarity between bioreactor and plate cultures. (A) Hypertrophic indices were determined as the total amount of protein present divided by the amount of DNA present. No statistically significant differences were found, indicating that the overall composition of the cultures was stable over the 6-day time course. Bioreactors on culture day 6 tended to have slightly higher indices. This is consistent with the previously noted accumulation of ECM material in this type of 3D aggregate culture (Akins et al., 1999; Akins and Sefton, 2001). (B) The expression of cardiac troponin I (Tnni3) was used to evaluate active muscle biosynthesis in bioreactor and plate samples. $\mathrm{Ct}$ values are presented for quantitative PCR reactions; no significant differences were found between the two systems, indicating similar levels in bioreactor and plate cultures as reported previously (Akins et al., 1999), and stable expression of this cardiomyocyte structural gene over time. Data are means of triplicate determinations for each sample \pm standard deviation. 
qPCR
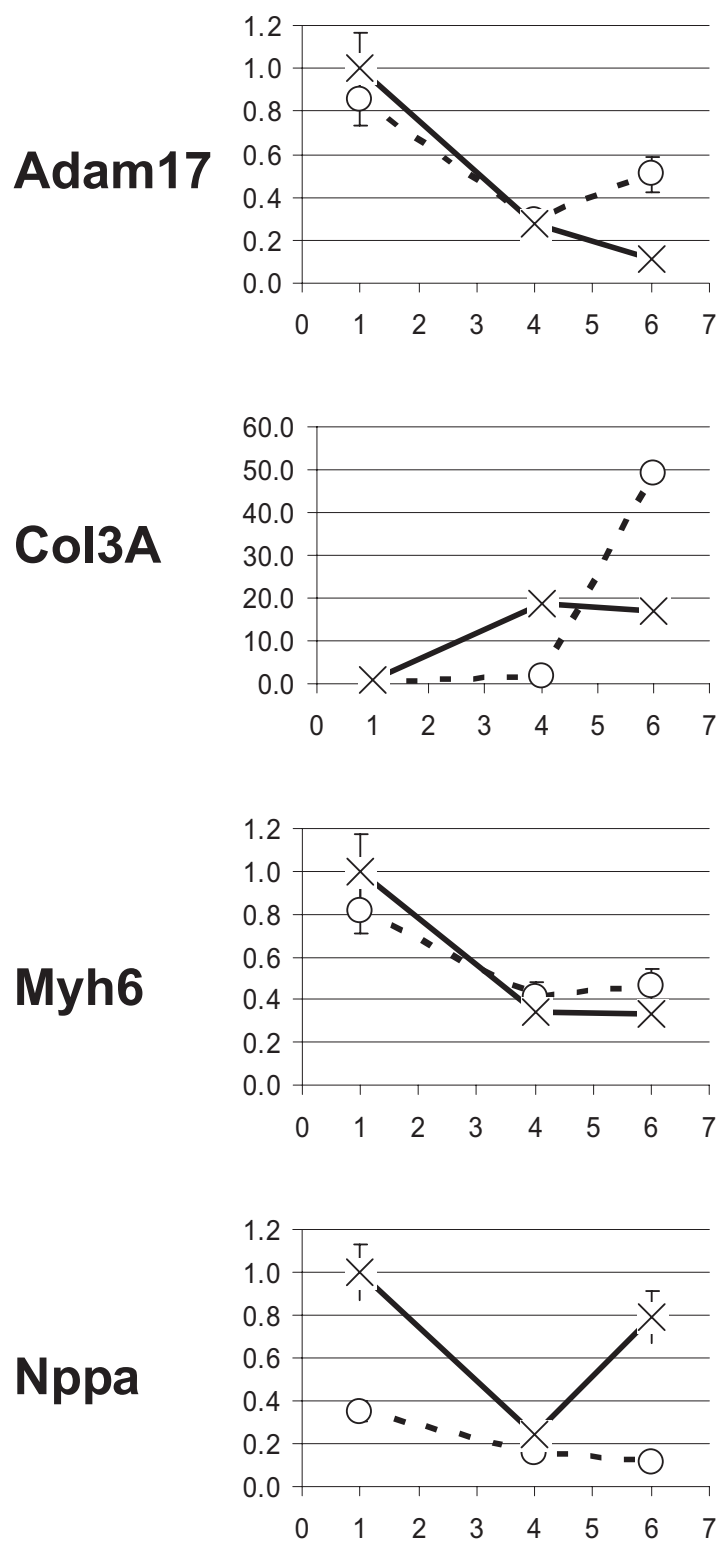

Microarray
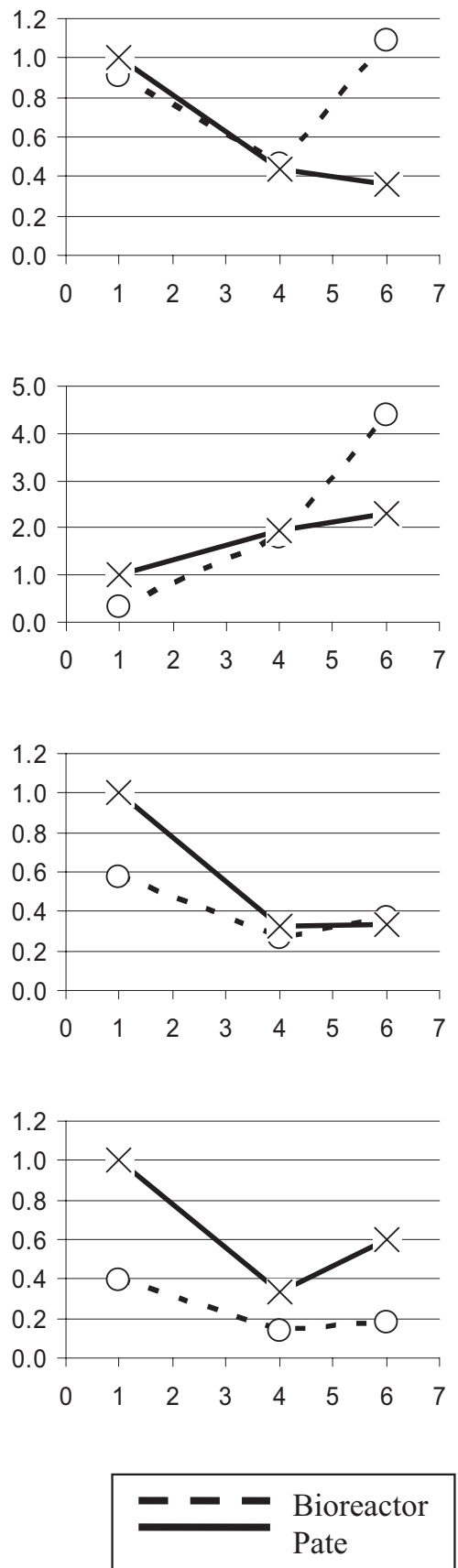

FIG. 2. Validation of microarray expression patterns. Data are presented for four control genes comparing real-time quantitative PCR (qPCR) expression levels with microarray-derived values. Y-axis values indicate the fold differences relative to the day 1 plate value as normalized to cardiac troponin I (Tnni3) expression. Microarray data were determined from the average value for all relevant probe sets; qPCR data were determined as the average fold difference based on triplicate determinations for each of the 12 samples analyzed by microarray.

\section{DAVID analysis of overrepresented genes}

In order to determine whether the filtered data set included genes associated with known pathways, a statistical method based on gene ontologies was used to identify groups that were significantly overrepresented in the filtered data set. The analysis generated an EASE score, which is a Fisher Exact Statistic, to indicate the probability that a set of genes was found by chance sampling of the annotated genes on the RG-U34A chip. Table 2 


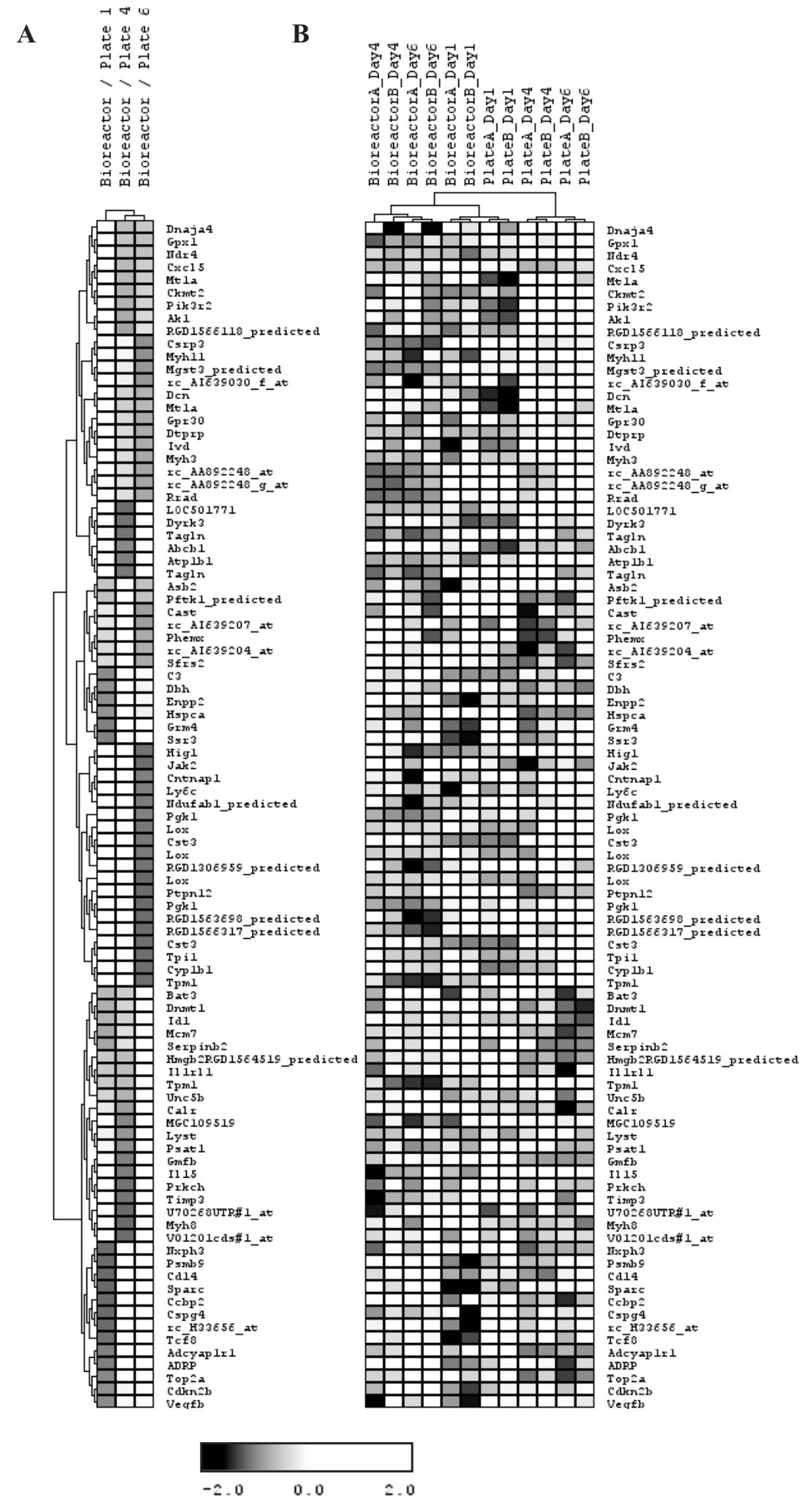

FIG. 3. Heat maps of filtered data set. The results of hierarchical clustering analysis are presented graphically. Probe sets are organized by row with each column representing a sample or average values for a group of samples. For visualization, data were normalized by row to determine a $z$-score (i.e., the value's difference from the row mean divided by the standard deviation for the row) and are presented across a linear gray scale from -2 (black) to +2 (white). (A) Probe set groupings determined by hierarchical clustering of the average ratio of values between bioreactor and plate samples from both experiments. The analysis indicates that several distinct patterns of expression were present among the filtered probe sets. (B) Sample groupings determined by hierarchical clustering across all 12 samples. Associations among the samples suggest that the overall expression profile between bioreactors and plates was similar on day 1 but diverged thereafter. Note that the probe sets are arranged in the same order as in (A). 
shows the results of the analysis carried out using Web accessible tools available from DAVID on the National Institute of Allergy and Infectious Disease (NIAID) as described previously (Dennis et al., 2003; Hosack et al., 2003). Bioprocess gene ontologies were queried, and all hits with EASE score $<0.05$ are reported. Interestingly, a small number of genes associated with muscle development, morphogenesis, and organogenesis were significantly overrepresented in our list. These genes included Adcyap1r1, Cspg4, Csrp3, Dnmt1, Id1, Jak2, Myh3, Myh8, Myh11, Tagln (transgelin), Tpm1 (tropomyosin 1), and Unc5b (Table 3).

\section{DISCUSSION}

Rat heart cells form 3D, tissue-like aggregates when grown in bioreactors. A principal characteristic of these aggregates is an outer layer of endothelial cells (ECs), which surround an underlying layer of muscle and extracellular matrix (ECM) (Akins et al., 1999). Analysis of gene expression patterns suggests that this in vitro tissuegenesis was associated with developmental, morphogenic, and angiogenic molecular pathways. We conclude that $3 \mathrm{D}$ cardiac cell aggregates offer convenient and accessible model systems for evaluating cell-directed tissuegenesis and for investigating the pathways affecting multicellular architecture in tissue engineering and regenerative therapies. Data from other studies support this overall finding. For example, using dramatically different approaches, Dennis and coworkers (Baar et al., 2005; Birla et al., 2005a, 2005b) and Watzka et al. (2004) recently described self-organization and neovascularization of $3 \mathrm{D}$ heart cell aggregates. Interestingly, the ECs in the long-term cultures described by the latter group were only found deep inside the aggregates and not on the surface as seen in our shortterm bioreactor cultures. Kelm et al. (2004) indicate that cardiomyocytes initially appear on the surface of their selfassembling constructs, whereas Just et al. (2006) report that fibroblast-like cells locate to the surface of their 3D aggregates. These variations in cell-type distribution may arise due to differences in culture conditions. In particular, our system employs a serum-free medium as opposed to one including up to $10 \%$ serum, and different lots of sera are known to have varying mitogenic and growth factor-mediated effects on cell phenotype and multicellular assembly. In addition, our cultures are quiescently rotated, which may allow cells to grow more readily in $3 \mathrm{D}$ but exposes them to low levels of fluid shear along the aggregate surface. The fluid environment within bioreactors can dramati- cally influence cell phenotype and multicellular organization (Vunjak-Novakovic, 2006), and mechanical influences may account for some of the differences seen among the different culture approaches. It should be pointed out that the fluid environment within rotating VueLife bags appears similar to other rotating-wall bioreactors, including the HARV bioreactor (Akins et al., 1997, 1999), and routine bioassay parameters, such as cellular differentiation status, glucose utilization rates, pressure of oxygen $\left(\mathrm{pO}_{2}\right)$, pressure of carbon dioxide $\left(\mathrm{pCO}_{2}\right)$, and intermediary metabolic activities, are all similar in VueLife and HARV bioreactors (unpublished observation).

The genes used to validate the chip-based expression patterns were selected because of their biological significance and association with cardiac development and function. ADAM-17 has been linked to heart development; it is a major sheddase for heparin-binding epidermal growth factor (EGF)-like growth factor and has been associated with the release of neuregulins $\beta 1$ and $\beta 2$ by fibroblasts (Horiuchi et al., 2005). NppA results in the production of atrial natriuretic peptide (ANP), which is secreted by myocytes in adult atria to modify blood volume and salt balance. ANP is expressed throughout the heart during development and may be an important modulator of myocyte growth (Cameron and Ellmers, 2003). Alpha myosin heavy chain is one of the two isoforms of sarcomeric myosin expressed in the heart. It is the predominant form of myosin in rat ventricular cardiomyocytes, and mutations in Myh6 have been associated with dilated and hypertrophic cardiomyopathies (Carniel et al., 2005). Finally, collagen III is a critical component of the cardiac ECM and a mediator of myocardial organization (Simpson et al., 1994). Thus, an enzyme, a secreted factor, a contractile protein, and an ECM molecule, all important in the heart, were included in the validation. The expression patterns were very similar in the chip and qPCR detections, and with the exception of Col3A, the relative levels of expression determined by qPCR and chip detection were remarkably close. The discrepancy in relative Col3A levels may be accounted for by probe or primer-binding efficiencies; however, we did not investigate this possibility.

Data reduction of the gene set was carried out based on simple criteria that took advantage of the experimental design and the characteristics of the parallel bioreactor and plate culture systems. In previous work, we found that the overall cellular composition of bioreactor and plate cultures was remarkably similar with major differences only arising in the organization of cells (Akins et al., 1999). Since the bulk of culture material in the present study was needed for RNA

Table 2. EASE Analysis Results ${ }^{\mathrm{a}}$

\begin{tabular}{lccc}
\hline Category & $\begin{array}{c}\text { Genes in list } \\
(39 \text { possible })\end{array}$ & $\begin{array}{c}\text { Genes in population } \\
(2188 \text { possible })\end{array}$ & EASE score \\
\hline (i) Muscle development & 6 & 29 & 0.00000758 \\
(ii) Muscle contraction & 4 & 17 & 0.000174 \\
(iii) Cell motility & 5 & 46 & 0.00111 \\
(iv) Development & 12 & 313 & 0.00617 \\
(v) Organogenesis & 9 & 201 & 0.00718 \\
(vi) Morphogenesis & 9 & 207 & 0.00869 \\
\hline
\end{tabular}

${ }^{a}$ Categories are bioprocess gene ontologies. EASE score is the Fisher Exact statistic for the likelihood that the number of genes found in the filtered list occurred by chance sampling of the RG-U34A probe set population. 

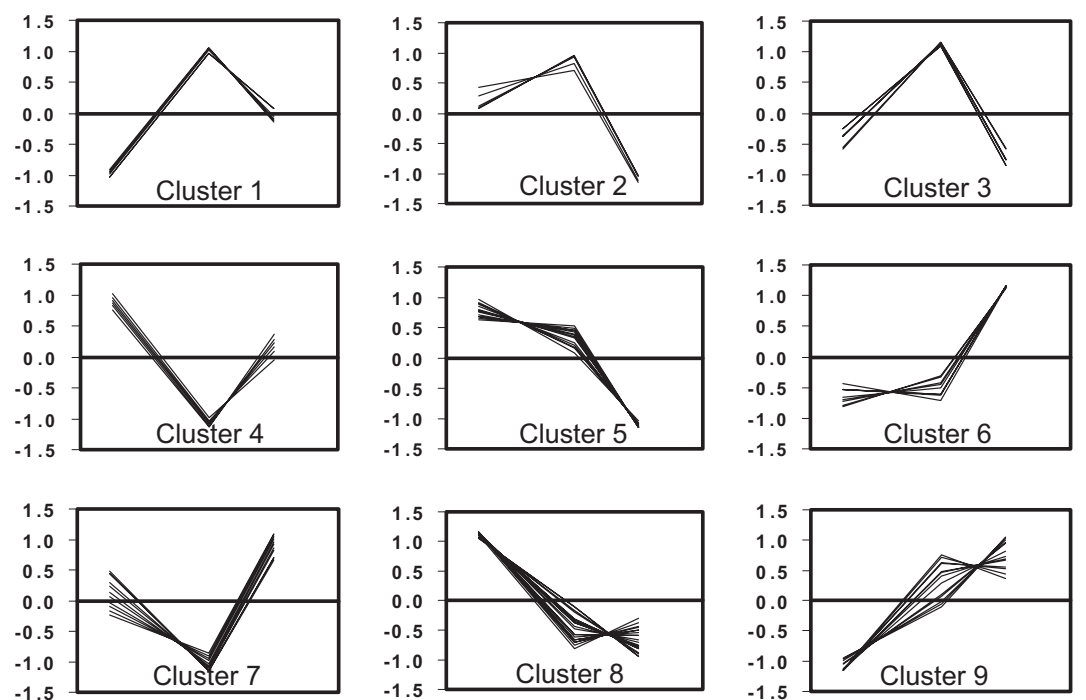

B Cluster \# and Gene Symbol

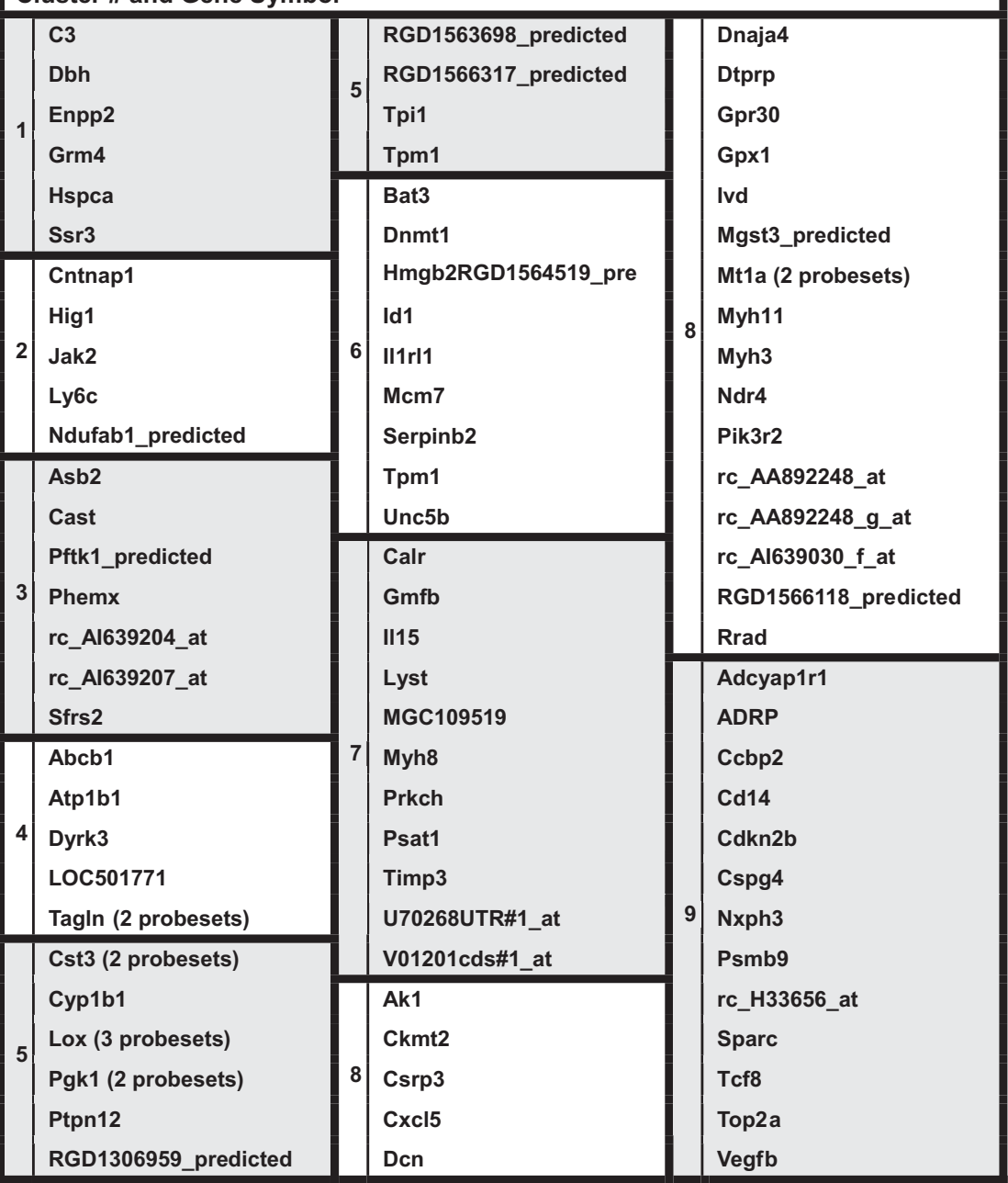

FIG. 4. Gene clustering. Analysis of the 93 probe sets in our filtered data indicated nine distinct clusters based on the relative pattern of gene expression between bioreactors and plates over time in culture. (A) Graphs showing the ratios of bioreactor to plate signals at days 1, 4, and 6 indicating the expression profile of the genes in each cluster. The raw data were normalized for each probe set to determine a $z$-score (i.e., the number of standard deviations above or below the mean for the probe set). The horizontal line indicates the average value for the row; a positive slope indicates a relative increase in bioreactor versus plate signal, and a negative slope indicates a relative decrease. (B) List of the genes present in each cluster. Cases where more than one probe set was present for a given gene in a given cluster are denoted accordingly. 
Table 3. Genes Contributing to Overrepresented Categories ${ }^{\mathrm{a}}$

\begin{tabular}{|c|c|c|c|c|}
\hline Gene symbol & $\begin{array}{c}\text { Day } 1 \text { expression } \\
\text { (average } B / P \text { ) }\end{array}$ & $\begin{array}{c}\text { Day } 4 \text { expression } \\
\text { (average } B / P \text { ) }\end{array}$ & $\begin{array}{c}\text { Day } 6 \text { expression } \\
\text { (average } B / P \text { ) }\end{array}$ & $\begin{array}{c}\text { EASE } \\
\text { categories }\end{array}$ \\
\hline Adcyap1r1 & 0.644 (A/A) & $1.380(\mathrm{~A} / \mathrm{A})$ & 2.549 (P/A) & (iv) \\
\hline Cspg4 & $0.398(\mathrm{~A} / \mathrm{P})$ & $0.755(\mathrm{~A} / \mathrm{A})$ & $0.820(\mathrm{~A} / \mathrm{A})$ & (iv)-(vi) \\
\hline Csrp3 & $0.726(\mathrm{P} / \mathrm{P})$ & $0.368(\mathrm{P} / \mathrm{P})$ & $0.222(\mathrm{P} / \mathrm{P})$ & (iv)-(vi) \\
\hline Dnmt1 & $0.935(\mathrm{P} / \mathrm{P})$ & $1.100(\mathrm{P} / \mathrm{P})$ & 2.497 (P/A) & (iv) \\
\hline Id1 & 1.242 (P/A) & $1.312(\mathrm{P} / \mathrm{P})$ & 1.841 (P/A) & (iv)-(vi) \\
\hline Jak2 & $1.996(\mathrm{P} / \mathrm{P})$ & $2.145(\mathrm{P} / \mathrm{P})$ & $1.341(\mathrm{P} / \mathrm{P})$ & (iv) \\
\hline Myh11 & 0.442 (A/A) & $0.379(\mathrm{~A} / \mathrm{P})$ & $0.338(\mathrm{~A} / \mathrm{P})$ & (i)-(vi) \\
\hline Myh3 & $0.986(\mathrm{~A} / \mathrm{A})$ & 0.547 (A/P) & $0.464(\mathrm{~A} / \mathrm{P})$ & (i)-(vi) \\
\hline Myh8 & $2.785(\mathrm{P} / \mathrm{A})$ & $1.866(\mathrm{~A} / \mathrm{A})$ & $4.232(\mathrm{~A} / \mathrm{A})$ & (i)-(vi) \\
\hline Tagln & $0.732(\mathrm{P} / \mathrm{P})$ & $0.358(\mathrm{P} / \mathrm{P})$ & $0.568(\mathrm{P} / \mathrm{P})$ & (i), (iv)-(vi) \\
\hline Tpm1 & $0.641(\mathrm{P} / \mathrm{P})$ & $0.560(\mathrm{P} / \mathrm{P})$ & $0.469(\mathrm{P} / \mathrm{P})$ & (i)-(vi) \\
\hline Unc $5 b$ & $0.983(\mathrm{P} / \mathrm{P})$ & $0.831(\mathrm{P} / \mathrm{P})$ & $2.528(\mathrm{P} / \mathrm{P})$ & (ii)-(vi) \\
\hline
\end{tabular}

${ }^{a}$ Details on the specific genes are given in the text. Numerical values presented are the average ratio between expression levels for bioreactor signal (B) divided by plate signal (P) including all probe sets for that gene and across both experiments. Present/absent calls are indicated parenthetically and given as the call for the bioreactor samples over the call for the plate samples $(A=a b s e n t ; P=$ present). The EASE categories refer to the designations given in Table 2: (i) Muscle development, (ii) Muscle contraction, (iii) Cell motility, (iv) Development, (v) Organogenesis, and (vi) Morphogenesis.

EASE: Expression Analysis Systematic Explorer.

isolation, complete recharacterizations were not repeated here, and the assessment of cellular content was limited to determinations of hypertrophic index and troponin I expression level. These validation assays are consistent with the remarkable similarity seen in cellular content between 3D aggregate and 2D plate cultures.

Interestingly, hierarchical clustering of the 12 samples indicated that bioreactor and plate cultures were similar on day 1 but diverged thereafter. This was somewhat unexpected; we had anticipated that the bioreactor and plate groups would form two distinct clusters. A simple explanation for similarities on day 1 is that during early phases of culture, cells in both systems necessarily access similar pathways. Principal events that are completed in the first $24 \mathrm{~h}$ of culture include the adhesion of all cell types and the onset of cardiomyocyte contractility. The clustering result suggests that the primary differences that distinguish bioreactor and plate cultures arise subsequent to these early events.

In order to better understand the trends in gene expression among the 93 probe sets, hierarchical clustering was also carried out on the average fold differences between bioreactor and plate samples. Of particular interest, several genes associated with angiogenesis (Cd14, Cspg4, Gmfb, Id1, Il15, Sparc, Unc5b, and Vegfb) were elevated in bioreactor culture on day 6 . These observations support the notion that $3 \mathrm{D}$ aggregate culture leads to the activation of angiogenic pathways in vitro.

EASE analysis indicated that a number of ontologies associated with muscle development and morphogenesis were overrepresented in our filtered data. Each of the 12 genes accounting for this result has a potentially significant role in cardiac tissuegenesis. There were six cytoskeletal proteins, including three myosin heavy chains: Myh11, which is smooth muscle isoform associated with closure of the ductus arteriosus (Morano et al., 2000); Myh8, which is a perinatal isoform associated with distal arthrogryposis and cardiac myxomas (Wilkes et al., 2005); and Myh3, which is an embryonically expressed isoform also asso- ciated with distal arthrogryposis but with no known cardiac tissue involvement (Toydemir et al., 2006). Additional cytoskeletal proteins included Csrp3, which is associated with cardiac muscle organization and hypertrophic cardiomyopathy (Bos et al., 2006); Tagln, which is expressed in vascular smooth muscle cells and cardiac myocytes (Lepore et al., 2005); and Tpm1 (Denz et al., 2004). Cspg4, a chondroitin sulfate proteoglycan (NG2) expressed by cardiomyocytes during development, is an ECM protein active in the formation of neovascular structures (Ozerdem et al., 2001). Two signaling mediators were present: Adcyap1r1, which is an adenylate cyclase activating peptide receptor expressed in the heart (Ushiyama et al., 2006), and Jak2, which is essential for the initial stages of cardiomyogenesis (Foshay et al., 2005). Dnmt1, which is a DNA (cytosine5-)-methyltransferase 1, is involved in maintenance methylation (Gonzalo et al., 2006) and was also on the list. Two genes associated with EC migration were also identified: Unc5b is expressed in specialized ECs that guide outgrowing capillaries in response to gradients of vascular endothelial growth factor (Eichmann et al., 2005), and Id1 activates EC migration after stimulation by bone morphogenetic protein (BMP) (Valdimarsdottir et al., 2002).

In addition to the ontologies identified by EASE analysis, the filtered data set contained 10 genes associated with hypoxia, ischemia, or response to stress or injury, and 13 genes associated with ECs, vascular smooth muscle cells, or vasculogenesis/ angiogenesis. The hypoxia-related/stress-related genes included Abcb1, Ak1, Atp1b1, Cast, Cxx15, Gpx1, Hig1, Hspca, I11rl1, Mt1a, and Pgk1. Although the expression patterns for these genes varied, Hig1, which is hypoxia-induced gene (Wang et al., 2006), and Pgk1, which is upregulated in hypoxia, are both relatively elevated in day 6 plate cultures, suggesting that the plates are relatively hypoxic compared to the bioreactors. This difference may be related to local cellular microenvironments and is consistent with improved mixing in the bioreactor cul- 
tures. The 13 genes associated with ECs and blood vessels included Cd14, Cspg4, Dcn, Gmfb, Id1, Il15, Ly6c, Myh11, Ndr4, Sparc, Tagln, Unc5b, and Vegfb. The presence of these genes in our filtered list suggests that vasculogenic/angiogenic pathways are differentially expressed in bioreactors and plates. Especially interesting is the observation that Unc5b, which drives endothelial tip guidance during angiogenesis, and Id1, which is sufficient and necessary for BMP-mediated EC migration, are both elevated in bioreactors, suggesting that EC migration occurs in the bioreactors to a greater extent than in the plates. This is consistent with previous observations that 3D aggregate cultures of cardiac cells epithelialize (Sperelakis, 1978; Akins et al., 1999; Akins and Sefton, 2001; Zimmermann et al., 2004).

Overall our results suggest that pathways associated with muscle development, muscle contraction, cell motility, and organogenesis/morphogenesis are differentially modulated in bioreactor versus plate cultures. These differences occur in the timeframe during which NRHCs establish tissue-like architecture in bioreactors, and bioreactor cultures may offer a convenient and accessible model for investigating mechanisms controlling in vitro cardiac tissuegenesis.

\section{ACKNOWLEDGMENTS}

This work was supported by the National Aeronautics and Space Administration (NAG9-1339), the National Center for Research Resources (NIH 1P20-RR020173-01), and the Nemours Foundation.

\section{REFERENCES}

AKINS, R., McLAUGHLIN, T., BOYCE, B., GILMOUR, L., and GRATTON, K. (2004). Exogenous metalloporphyrins alter the organization and function of cultured neonatal rat heart cells via modulation of heme oxygenase activity. J Cell Physiol 201, 26-34.

AKINS, R., SCHROEDL, N., GONDA, S., and HARTZELL, C. (1997). Neonatal rat heart cells cultured in simulated microgravity. In Vitro Cell Dev Biol Anim 33, 337-343.

AKINS, R.E. (2002). Cardiac tissue. In Methods of Tissue Engineering. A. Atala and R. Lanza, eds. (Academic Press, San Diego, CA), pp. 915-925.

AKINS, R.E., and SEFTON, M.V. (2001). Tissue engineering a heart. New Surg 1, 26-32.

AKINS, R.E., BOYCE, R.A., MADONNA, M.L., SCHROEDL, N.A., GONDA, S.R., MCLAUGHLIN, T.A., and HARTZELL, C.R. (1999). Cardiac organogenesis in vitro: reestablishment of three-dimensional tissue architecture by dissociated neonatal rat ventricular cells. Tissue Eng 5, 103-118.

BAAR, K., BIRLA, R., BOLUYT, M.O., BORSCHEL, G.H., ARRUDA, E.M., and DENNIS, R.G. (2005). Self-organization of rat cardiac cells into contractile 3-D cardiac tissue. FASEB J 19, 275-277.

BIRLA, R.K., BORSCHEL, G.H., and DENNIS, R.G. (2005a). In vivo conditioning of tissue-engineered heart muscle improves contractile performance. Artif Organs 29, 866-875.

BIRLA, R.K., BORSCHEL, G.H., DENNIS, R.G., and BROWN, D.L. (2005b). Myocardial engineering in vivo: formation and characterization of contractile, vascularized three-dimensional cardiac tissue. Tissue Eng 11, 803-813.

BISSELL, M.J., RIZKI, A., and MIAN, I.S. (2003). Tissue architecture: the ultimate regulator of breast epithelial function. Curr Opin Cell Biol 15, 753-762.

BOS, J.M., POLEY, R.N., NY, M., TESTER, D.J., XU, X., VATTA, M., TOWBIN, J.A., GERSH, B.J., OMMEN, S.R., and ACKERMAN,
M.J. (2006). Genotype-phenotype relationships involving hypertrophic cardiomyopathy-associated mutations in titin, muscle LIM protein, and telethonin. Mol Genet Metab 88, 78-85.

CAMERON, V.A., and ELLMERS, L.J. (2003). Minireview: natriuretic peptides during development of the fetal heart and circulation. Endocrinology 144, 2191-2194.

CARNIEL, E., TAYLOR, M.R., SINAGRA, G., DI LENARDA, A., KU, L., FAIN, P.R., BOUCEK, M.M., CAVANAUGH, J., MIOCIC, S., SLAVOV, D., GRAW, S.L., FEIGER, J., ZHU, X.Z., DAO, D., FERGUSON, D.A., BRISTOW, M.R., and MESTRONI, L. (2005). Alpha-myosin heavy chain: a sarcomeric gene associated with dilated and hypertrophic phenotypes of cardiomyopathy. Circulation 112, 54-59.

DENNIS, G., JR., SHERMAN, B.T., HOSACK, D.A., YANG, J., GAO, W., LANE, H.C., and LEMPICKI, R.A. (2003). DAVID: database for annotation, visualization, and integrated discovery. Genome Biol 4, P3.

DENZ, C.R., NARSHI, A., ZAJDEL, R.W., and DUBE, D.K. (2004). Expression of a novel cardiac-specific tropomyosin isoform in humans. Biochem Biophys Res Commun 320, 1291-1297.

EICHMANN, A., LE NOBLE, F., AUTIERO, M., and CARMELIET, P. (2005). Guidance of vascular and neural network formation. Curr Opin Neurobiol 15, 108-115.

EISEN, M.B., SPELLMAN, P.T., BROWN, P.O., and BOTSTEIN, D. (1998). Cluster analysis and display of genome-wide expression patterns. Proc Natl Acad Sci USA 95, 14863-14868.

ESCHENHAGEN, T., and ZIMMERMANN, W.H. (2005). Engineering myocardial tissue. Circ Res 97, 1220-1231.

FOSHAY, K., RODRIGUEZ, G., HOEL, B., NARAYAN, J., and GALLICANO, G.I. (2005). JAK2/STAT3 directs cardiomyogenesis within murine embryonic stem cells in vitro. Stem Cells 23, 530-543. GONZALO, S., JACO, I., FRAGA, M.F., CHEN, T., LI, E., ESTELLER, M., and BLASCO, M.A. (2006). DNA methyltransferases control telomere length and telomere recombination in mammalian cells. Nat Cell Biol 8, 416-424.

HORIUCHI, K., ZHOU, H.M., KELLY, K., MANOVA, K., and BLOBEL, C.P. (2005). Evaluation of the contributions of ADAMs 9, $12,15,17$, and 19 to heart development and ectodomain shedding of neuregulins beta1 and beta2. Dev Biol 283, 459-471.

HOSACK, D.A., DENNIS, G., JR., SHERMAN, B.T., LANE, H.C., and LEMPICKI, R.A. (2003). Identifying biological themes within lists of genes with EASE. Genome Biol 4, R70.

JUST, L., KURSTEN, A., BORTH-BRUHNS, T., LINDENMAIER, W., ROHDE, M., DITTMAR, K., and BADER, A. (2006). Formation of three-dimensional fetal myocardial tissue cultures from rat for longterm cultivation. Dev Dyn 235, 2200-2209.

KELM, J.M., EHLER, E., NIELSEN, L.K., SCHLATTER, S., PERRIARD, J.C., and FUSSENEGGER, M. (2004). Design of artificial myocardial microtissues. Tissue Eng 10, 201-214.

LEPORE, J.J., CHENG, L., MIN LU, M., MERICKO, P.A., MORRISEY, E.E., and PARMACEK, M.S. (2005). High-efficiency somatic mutagenesis in smooth muscle cells and cardiac myocytes in SM22alpha-Cre transgenic mice. Genesis 41, 179-184.

MCCARL, R.L., HARTZELL, C.R., SCHROEDL, N., KUNZE, E., and ROSS, P.D. (1980). Mammalian heart cells in culture. In Hearts and Heart-Like Organs. Vol. 3. G.H. Bourne, ed. (Academic Press, New York), pp. 1-44.

MORANO, I., CHAI, G.X., BALTAS, L.G., LAMOUNIER-ZEPTER, V., LUTSCH, G., KOTT, M., HAASE, H., and BADER, M. (2000). Smooth-muscle contraction without smooth-muscle myosin. Nat Cell Biol 2, 371-375.

NATIONAL INSTITUTES OF HEALTH (1999). Working Group on Tissuegenesis and Organogenesis for Heart, Lung, and Blood Applications. www.nhlbi.nih.gov/meetings/workshopd/tissueg.1.htm.

OZERDEM, U., GRAKO, K.A., DAHLIN-HUPPE, K., MONOSOV, E., and STALLCUP, W.B. (2001). NG2 proteoglycan is expressed exclusively by mural cells during vascular morphogenesis. Dev Dyn 222, 218-227.

SAEED, A.I., SHAROV, V., WHITE, J., LI, J., LIANG, W., BHAGABATI, N., BRAISTED, J., KLAPA, M., CURRIER, T., THIAGARAJAN, M., STURN, A., SNUFFIN, M., REZANTSEV, A., POPOV, D., RYLTSOV, A., KOSTUKOVICH, E., BORISOVSKY, I., LIU, Z., VINSAVICH, A., TRUSH, V., and QUACKENBUSH, J. 
(2003). TM4: a free, open-source system for microarray data management and analysis. Biotechniques 34, 374-378.

SIMPSON, D.G., TERRACIO, L., TERRACIO, M., PRICE, R.L., TURNER, D.C., and BORG, T.K. (1994). Modulation of cardiac myocyte phenotype in vitro by the composition and orientation of the extracellular matrix. J Cell Physiol 161, 89-105.

SPERELAKIS, N. (1978). Cultured heart cell reaggregate model for studying cardiac toxicology. Environ Health Perspect 26, 243-267.

THOM, T., HAASE, N., ROSAMOND, W., HOWARD, V.J., RUMSFELD, J., MANOLIO, T., ZHENG, Z.J., FLEGAL, K., O'DONNELL, C., KITTNER, S., LLOYD-JONES, D., GOFF, D.C., JR., HONG, Y., ADAMS, R., FRIDAY, G., FURIE, K., GORELICK, P., KISSELA, B., MARLER, J., MEIGS, J., ROGER, V., SIDNEY, S., SORLIE, P., STEINBERGER, J., WASSERTHIEL-SMOLLER, S., WILSON, M., and WOLF, P. (2006). Heart disease and stroke statistics-2006 update: a report from the American Heart Association Statistics Committee and Stroke Statistics Subcommittee. Circulation 113, e85-e151.

TOYDEMIR, R.M., RUTHERFORD, A., WHITBY, F.G., JORDE, L.B., CAREY, J.C., and BAMSHAD, M.J. (2006). Mutations in embryonic myosin heavy chain (MYH3) cause Freeman-Sheldon syndrome and Sheldon-Hall syndrome. Nat Genet 38, 561-565.

USHIYAMA, M., SUGAWARA, H., INOUE, K., KANGAWA, K., YAMADA, K., and MIYATA, A. (2006). Characterization of the PAC1 variants expressed in the mouse heart. Ann N Y Acad Sci 1070, 586-590.

VALDIMARSDOTTIR, G., GOUMANS, M.J., ROSENDAHL, A., BRUGMAN, M., ITOH, S., LEBRIN, F., SIDERAS, P., and TEN DIJKE, P. (2002). Stimulation of Id1 expression by bone morphogenetic protein is sufficient and necessary for bone morphogenetic proteininduced activation of endothelial cells. Circulation 106, 2263-2270.

VUNJAK-NOVAKOVIC, G. (2006). Cardiac tissue engineering: effects of bioreactor flow environment on tissue constructs. J Chem Technol Biotechnol 81, 485-490.
WANG, J., CAO, Y, CHEN, Y, GARDNER, P , and STEINER, D.F. (2006). Pancreatic beta cells lack a low glucose and O2-inducible mitochondrial protein that augments cell survival. Proc Natl Acad Sci USA 103, 10636-10641.

WATZKA, S.B., STEINER, M., SAMORAPOOMPICHIT, P., GROSS, K., COLES, J.G., WOLNER, E., and WEIGEL, G. (2004). Establishment of vessel-like structures in long-term three-dimensional tissue culture of myocardium: an electron microscopy study. Tissue Eng 10, 1684-1694.

WILKES, D., MCDERMOTT, D.A., and BASSON, C.T. (2005). Clinical phenotypes and molecular genetic mechanisms of Carney complex. Lancet Oncol 6, 501-508.

ZIMMERMANN, W.H., MELNYCHENKO, I., and ESCHENHAGEN, T. (2004). Engineered heart tissue for regeneration of diseased hearts. Biomaterials 25, 1639-1647.

ZIMMERMANN, W.H., SCHNEIDERBANGER, K., SCHUBERT, P., DIDIE, M., MUNZEL, F., HEUBACH, J.F., KOSTIN, S., NEUHUBER, W.L., and ESCHENHAGEN, T. (2002). Tissue engineering of a differentiated cardiac muscle construct. Circ Res 90, 223-230.

Address reprint requests to:

Robert E. Akins, Jr., Ph.D.

Tissue Engineering and Regenerative Medicine Laboratory

Nemours Biomedical Research

A.I. duPont Hospital for Children Wilmington, DE 19803

E-mail: rakins@nemours.org

Received for publication November 22, 2006; received in revised form January 25, 2007; accepted February 7, 2007. 